\title{
Effects of tannase-converted green tea extract on skeletal muscle development
}

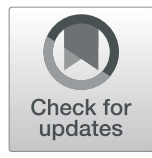

Ki-Bae Hong ${ }^{1}$, Hee-Seok Lee ${ }^{2}$, Jeong Sup Hong ${ }^{3}$, Dong Hyeon Kim ${ }^{4}$, Joo Myung Moon ${ }^{4}$ and Yooheon Park ${ }^{5^{*}}$

\begin{abstract}
Background: The aim of this study was to investigate the effect of tannase-converted green tea extract with a high $(-)$-epicatechin (EC), (-)-epigallocatechin (EGC), and gallic acid (GA) content on myotube density and fusion in normal and oxidative stress-induced C2C12 skeletal muscle cells. Although the use of green tea extract is considered beneficial, cellular and molecular mechanisms of action of tannase-converted green tea extracts that are used as potential muscle growth materials have not been thoroughly studied.

Methods: This study used histological analysis and molecular biology techniques, and compared the results with those for AMPK activator 5-aminoimidazole-4-carboxamide-1- $\beta$-D-ribonucleoside (AICAR) and green tea extracts.

Results: The myotube density of normal and oxidative stress-induced C2C12 cells was significantly higher in the tannase-converted green tea extract-treated group than that observed in the other groups (normal cells: $P<0.01$; oxidative stress-induced cells: $P<0.05$ ). In addition, tannase-converted green tea extract and green tea extract treatments significantly upregulated the genetic expression of myogenin, Myf5, and MyoD $(P<0.05)$. The levels of AMP-activated protein kinase-a (AMPKa) and muscle RING-finger protein-1 (MuRF-1) in the tannase-converted green tea extract group were higher than those in the AICAR and green tea extract groups $(P<0.05)$.

Conclusions: Taken together, our findings describe that the high levels of EC, EGC, and GA in the tannaseconverted green tea extract are attributable to the morphological changes in C2C12 cells and intercellular signaling pathways. Therefore, tannase-converted green tea extract can be used in the treatment of sarcopenia.
\end{abstract}

Keywords: Tannase-converted green tea extract, (-)-epicatechin, (-)-epigallocatechin, Skeletal muscle mass, Sarcopenia

\section{Background}

Aging is a predominant risk factor for common diseases, and previous studies have focused on the age-related physiological changes occurring in the molecular and cellular mechanisms [1]. In addition, cell senescence is a response to a variety of stressors and is a major target for therapeutic application and antiaging therapy. The loss of skeletal muscle associated with aging causes functional disability due to the loss of strength, risk of falls, fracture, and loss of autonomy [2]. Although the prevalence of sarcopenia is high in individuals whose age is $\geq 60$ years, accounting for $5-13 \%$ of all adults [3], the number of patients with sarcopenia is expected to rise as the aging population continues to increase globally. Skeletal muscle is the dominant organ system in locomotion and energy

\footnotetext{
* Correspondence: ypark@dongguk.edu

${ }^{5}$ Department of Food Science and Biotechnology, Dongguk University,

Goyang 10326, Republic of Korea

Full list of author information is available at the end of the article
}

metabolism, and its differentiation, growth and metabolism are regulated by neurotransmitters, hormones, growth factors, cytokines, and nutritional factors [4]. In addition, the induction sarcopenia is involved in one of several underlying mechanisms of major complications, and physical inactivity is known to increase chronic reactive oxygen species (ROS) overproduction during the progression of sarcopenia [5].

Even though the adapted physical activity, vitamin D administration and Mediterranean diet are a possible nonpharmacologic treatment to prevent or treat muscle atrophy [6-8], the development of an effective method for its management and treatment is still required. Recently, the use of botanical extracts and nutraceutical compounds via dietary sources has been focused on, to enhance muscle growth and physiological activity. Several botanicals (citrus, coffee, ginger, ginseng, grape, and turmeric, etc.) are known to have a significant level of activity in the prevention of muscle damage and

(c) The Author(s). 2020 Open Access This article is distributed under the terms of the Creative Commons Attribution 4.0 International License (http://creativecommons.org/licenses/by/4.0/), which permits unrestricted use, distribution, and 
pain resulting from inflammation and oxidative stress. More recent studies in animal models and in vitro demonstrate the antioxidative and anti-inflammatory roles of nutraceutical compounds including polyphenols, flavonoids, and phenolic acids through the modulation of the levels of proteins, plasma enzymes, cytokines, and receptors related to the immune response [9].

Green tea harvested from Camellia sinensis contains polyphenols and it is widely used in nutraceutical and pharmaceutical industries. Diverse studies have been conducted regarding tea production, the extraction process, storage, and optimum conditions [10]. In addition, an impressive number of studies have consistently assessed the role of green tea polyphenols in liver and heart diseases, and different types of methods for cancer prevention [11]. Most of the green tea polyphenols are flavanols, and a plant chemical known as a catechin, which is an antioxidant. The polyphenol components of green tea, such as (-)-epigallocatechin gallate (EGCG), (-)-epicatechin (EC), (-)-epigallocatechin (EGC), and (-)-epicatechin gallate (ECG) are used as antiinflammatory [12], and anti-oxidative [13].

Several approaches have been extensively applied to improve the total catechin content, function, and pharmacological properties of green tea, and several studies have reported that enzyme hydrolysate enhances total catechins and/or (-)-epicatechin content and biological properties [14]. (-)-Epicatechin has been reported to affect several different signaling pathways by giving rese to differences in tissue specificity, it consists of two aromatic rings linked by an oxygenated heterocycle with a 4-hydroxyl group [15]. Previous studies have revealed that green tea extract played a role in muscle recovery, but the effects of the enzyme-converted green tea catechins on skeletal muscle mass and relevant mechanisms are yet to be studied.

The purpose of this study was to investigate whether the effects of tannase-converted green tea extract with a high EC, EGC, and gallic acid (GA) content on myotube density, fusion, and muscle atrophy are greater than those of green tea extract in normal and oxidative stress-induced $\mathrm{C} 2 \mathrm{C} 12$ skeletal muscle cells. Therefore, in this study, results obtained with 5 '-AMP-activated protein kinase (AMPK) activator 5-aminoimidazole-4-carboxamide-1- $\beta$-D-ribonucleoside (AICAR) and green tea extract were compared using histological analysis and molecular biology techniques. Our findings describe the morphological changes occurring in the $\mathrm{C} 2 \mathrm{C} 12$ cell, intercellular signaling pathways associated with sarcopenia, and the therapeutic potential of EC, EGC, and GA obtained from tannase-converted green tea extract.

\section{Methods}

\section{Materials and chemicals}

Tannase-converted green tea extract and green tea extract were obtained from BTC Co. Ltd. (Ansan, South Korea). The green tea extract was hydrolyzed by tannase
(Kikkoman Biochemifa, Tokyo, Japan) and obtained the supernatant. The tannase-converted green tea extract was prepared as described in a previous study [16]. HPLC analytical grade standard EGCG, EGC, ECG, EC, GA, and caffeine were purchased from Sigma-Aldrich (St. Louis, MO, USA), and acetic acid and acetonitrile were obtained from Fisher Scientific (Pittsburgh, PA, USA). A specific activator (AICAR) was purchased from Sigma-Aldrich (St. Louis, MO).

\section{HPLC analysis}

The analysis of the catechin content was performed using an HPLC system (Waters e2695 Separations Module, USA) and a UV detection system, as described in previous reports [14]. The HPLC system for catechin, GA, and caffeine measurement used standard materials, and consisted of the Hypersil C18 column $(5 \mu \mathrm{m}, 25 \times 0.46 \mathrm{~cm} \mathrm{ID)}$ and a UV-Vis detector. The mobile phase contained $1 \%$ acetic acid (solvent A) and acetonitrile (solvent $\mathrm{B}$ ), with a linear gradient commencing at 92/8 (A/B ratio) and finishing at $73 / 27$ over $40 \mathrm{~min}$, at a flow rate of $1 \mathrm{~mL} / \mathrm{min}$.

\section{Cell cultures}

The $\mathrm{C} 2 \mathrm{C} 12$ mouse myoblast cell line (ATCC $\mathrm{CRL}^{\bullet} 772^{\mathrm{mm}}$ ) was obtained from the American Type Culture Collection (ATCC; Manassas, VA, USA). All cell types were maintained in Dulbecco's modified Eagle medium (DMEM) containing $10 \%$ fetal bovine serum (FBS) and $1 \%$ penicillinstreptomycin $(10,000 \mathrm{U} / \mathrm{mL})$ at $37^{\circ} \mathrm{C}$ in a humidified atmosphere of $5 \% \mathrm{CO}_{2}$ in air. To induce differentiation in $\mathrm{C} 2 \mathrm{C} 12$ cells, $5 \times 104$ cells were seeded in six-well plates and cultured in growth media until $80-90 \%$ confluence was attained. Then, the media were replaced with DMEM media containing $2 \%$ horse serum and $1 \%$ penicillin-streptomycin $(10,000$ $\mathrm{U} / \mathrm{mL}$ ). For the cell viability assay, differentiated $\mathrm{C} 2 \mathrm{C} 12$ cells were treated with tannase-converted green tea extract $(1,5$, $10,15$, and $20 \mu \mathrm{g} / \mathrm{mL})$ or green tea extract $(1,5,10,15$, and $20 \mu \mathrm{g} / \mathrm{mL})$ and cultured for $24 \mathrm{~h}$. A total of $15 \mu \mathrm{L}$ of 3-(4,5dimethylthiazol-2-yl)-2,5-diphenyltetrazolium bromide (MTT, Thermo Fisher Scientific, Lombard, IL, USA) was added to each well and incubation was carried out for $3 \mathrm{~h}$. One hundred microliters of DMSO were added to each well and incubation was carried out for $30 \mathrm{~min}$. Absorbance was measured at $560 \mathrm{~nm}$. The relative survival rate of the treated group was calculated based on the survival rate of the normal group that was not treated with $100 \%$ of the drug.

\section{Giemsa staining}

The Giemsa staining method of analysis was modified and performed according to the method described by Veliça [17]. C2C12 cells in wells were washed with phosphatebuffered saline (PBS), fixed with $100 \%$ methanol for $5 \mathrm{~min}$, and dried for $10 \mathrm{~min}$. The Jenner staining solution (BDH, Poole, UK) was diluted 1:3 in $1 \mathrm{mM}$ sodium phosphate 
buffer (Sigma-Aldrich, pH 5.6) and incubated for 5 min. After washing with PBS, the wells were incubated with 1 $\mathrm{mL}$ Giemsa staining solution $(\mathrm{BDH})$ that was diluted 1:10 times in $1 \mathrm{mM}$ sodium phosphate buffer for $10 \mathrm{~min}$ at room temperature. The wells were then washed 2-3 times with PBS and used to analyze the morphological changes in $\mathrm{C} 2 \mathrm{C} 12$ cells. The histological indices of $\mathrm{C} 2 \mathrm{C} 12$ myogenesis were analyzed, based on the method described by Veliça et al. [17].

\section{RNA isolation and mRNA expression}

The TRIzol ${ }^{\circ}$ reagent (Invitrogen, CA, USA) was used for total RNA isolation, according to the manufacturer's protocol. One microgram of total RNA was treated with RQ1 RNase-free DNase I (Promega, WI, USA) and reverse transcribed using SuperScript ${ }^{\circ}$ III Reverse Transcriptase (Invitrogen), using oligo (dT) primer. Real-time PCR (qRT-PCR) was performed using the Taqman Gene Expression Master Mix (Applied Biosystems, CA, USA), and quantitative analyses were conducted using the StepOne plus Software V. 2.0 (Applied Biosystems). All results were determined based on a validated control gene, $18 \mathrm{~S}$ RNA, using the $\Delta \Delta \mathrm{Ct}$ method [18]. Information for target genes used in qRT-PCR is as follows: Myogenin (NM_031189.2), Myf5 (NM_008656.5), MyoD (NM_010866.2), FOXO1 (NM_019739.3), FOXO3 (NM_019740.2), SOD (NM_011434.1), CAT (NM 009804.2), and GST (NM_001251762.2).

\section{Western Immunoblotting}

The cultured cells were washed with PBS 2-3 times, and $150 \mu \mathrm{L}$ of RIPA Buffer was added. The cells were lysed for $30 \mathrm{~min}$ and centrifuged at $12,000 \times \mathrm{g}$ for $10 \mathrm{~min}$ at $4{ }^{\circ} \mathrm{C}$. Protein concentration was quantified using standardizing BSA (bovine serum albumin). Ten $\mu \mathrm{g}$ of lysate was denatured with $10 \%$ Mini-protean $\mathrm{TGX}^{\mathrm{sw}}$ and transferred to a polyvinylidene difluoride (PVDF) membrane at $100 \mathrm{~V}$ for $1 \mathrm{~h}$. The membrane was blocked with TBST $(0.1 \%$ Tween $20+$ TBS) solution containing 5\% skim milk for $1 \mathrm{~h}$. The primary antibody was diluted with skimmed milk (1:1000) and the reaction was allowed to occur overnight at $4{ }^{\circ} \mathrm{C}$, after which washing was carried out 3 times using TBST. The HRP secondary antibody (horseradish peroxide (HRP) conjugated IgG secondary antibody (Cell Signaling, \#5157, 1:2000) was diluted 1: 1000 times, allowed to react for $2 \mathrm{~h}$ at $4{ }^{\circ} \mathrm{C}$, washed three times with TBST, and allowed to react with the ECL substrate. Protein levels were detected with a specific antibody, using the ChemiDoc $^{\text {th }}$ imaging systems (Bio-Rad, Hercules, CA).

\section{Statistical analysis}

All analyses were conducted using the R-software (version 3.2.5, The R Foundation, Vienna, Austria). P-values were derived from Duncan's multiple-range test, and a value of $P<0.05$ was considered to be statistically significant. Values are expressed as the means \pm standard deviation (SD) for each group, and all experiments were repeated 4 times.

\section{Results \\ The effects of Tannase-converted green tea extract on C2C12 Myogenesis and muscle regulatory factors}

In the present study, the significant difference in total catechin content in tannase-converted green tea extract containing high epicatechin content (EC) and green tea extract (CT) was investigated (Table 1) the changes in $\mathrm{C} 2 \mathrm{C} 12$ cell morphology were compared with those observed in AICAR and green tea extract groups (Fig. 1 and Additional file 1). To examine the effects of EC, CGC, and gallic acid (GA) on myogenesis, $\mathrm{C} 2 \mathrm{C} 12$ cells were cultured in the presence of $10 \mu \mathrm{g} / \mathrm{mL}$ EC for $12 \mathrm{~h}$ and the results were compared with those obtained with the use of $0.1 \mathrm{mM}$ AICAR and $5 \mu \mathrm{g} /$ $\mathrm{mL}$ CT. Solutions with these concentrations were used after a confirmation was obtained through the MTT (3-(4, 5-Dimethylthiazol-2-yl)-2,5-diphenyltetrazolium bromide) cell viability assay (data not shown). EC was found to increase myotube density and fusion (Fig. 1a). As shown in Fig. 3-1b, the extent of myotube formation was calculated to quantify the morphological changes, and similar measurements for the myotube density were observed after treatment. The myotube density was significantly higher in the AICAR-treated group (AICAR vs. control, 2.22-fold increase, $P<0.05$ ) and the EC group (EC vs. control, 3.66-fold increase, $P<0.01$ ).

We examined the mRNA expression of myogenin, Myf5 and $\mathrm{MyoD}$ to understand the effects of $\mathrm{EC}$ on the mechanism of $\mathrm{C} 2 \mathrm{C} 12$ myogenic differentiation. As shown in Fig. 1c-e, EC and CT significantly upregulated the expression of myogenin (EC vs. control, 2.19-fold increase, $P<$ 0.05; CT vs. control, 1.99-fold increase, $P<0.05)$, Myf5 (EC vs. control, 2.26-fold increase, $P<0.05$; CT vs. control, 2.62-fold increase, $P<0.05$ ), and MyoD (EC vs. control, 3.43-fold increase, $P<0.05$; CT vs. control, 3.50 -fold increase, $P<0.05)$. However, the the expression of myogenic regulatory factors did not significantly increase in the AICAR-treatment group. This study demonstrated the effects of EC on myogenic genes, such as myogenin, Myf5, and MyoD in C2C12 cells, and showed that EC and CT

Table 1 Catechin content during tannase treatment

\begin{tabular}{lllllll}
\hline Process & EGCG $(\mathrm{mg} / \mathrm{g})$ & EGC $(\mathrm{mg} / \mathrm{g})$ & ECG $(\mathrm{mg} / \mathrm{g})$ & EC $(\mathrm{mg} / \mathrm{g})$ & $\mathrm{GA}(\mathrm{mg} / \mathrm{g})$ & Caffeine $(\mathrm{mg} / \mathrm{g})$ \\
\hline Raw material & $601.02 \pm 09.21$ & $185.00 \pm 1.2$ & $99.35 \pm 0.45$ & $61.34 \pm 0.82$ & $1.66 \pm 0.29$ & $18.29 \pm 0.98$ \\
After enzyme reaction & - & $511.73 \pm 1.8$ & - & $106.20 \pm 1.43$ & $209.45 \pm 2.12$ & $14.95 \pm 0.85$ \\
\hline
\end{tabular}

Values are expressed as the mean \pm standard deviation 
A

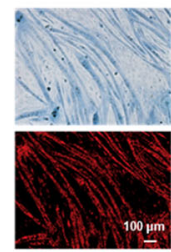

Control

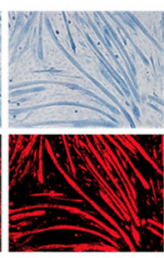

AICAR $0.1 \mathrm{mM}$
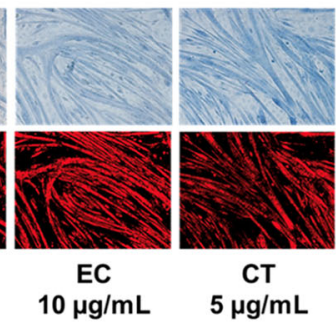

C. Myogenin

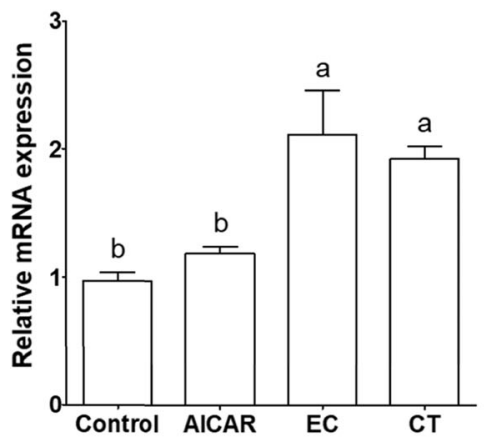

D. Myf5

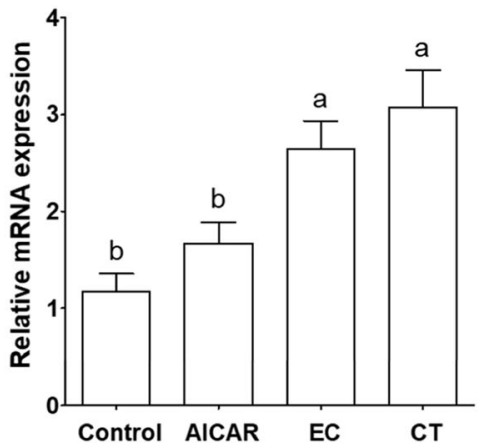

B
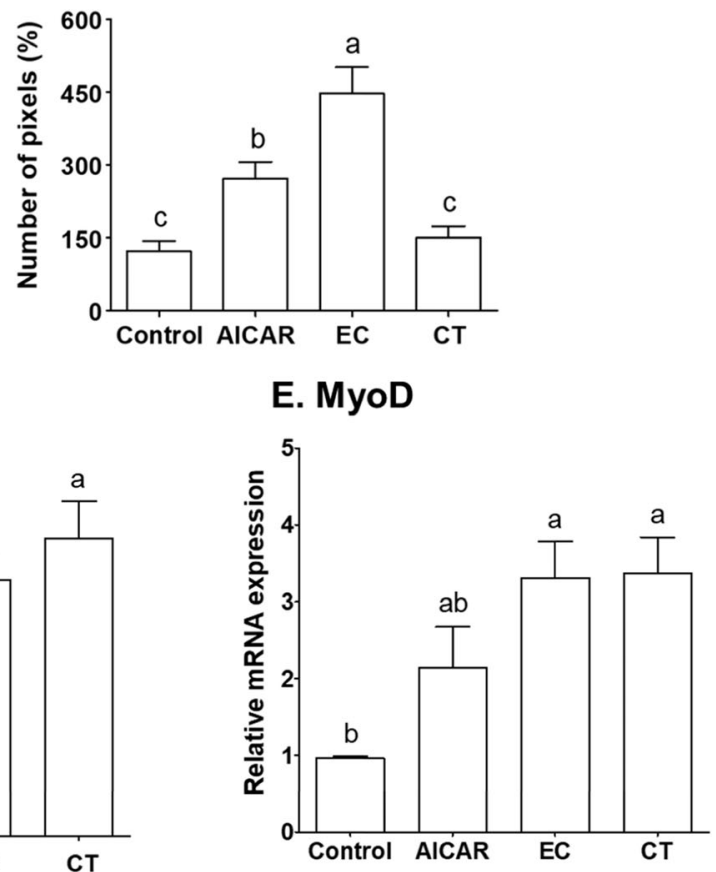

Fig. 1 The effects of tannase-treated catechin on ( $\mathbf{a}$ and $\mathbf{b})$ myotube formation and the gene expression of (c) myogenin, (d) Myf5 and (e) MyoD in C2C12 skeletal muscle cells. The myotube density was calculated as the sum of pixels attributed to tones 0-75. Each value represents the mean \pm SE. Different letters indicate significant differences at $P<0.05$ according to Tukey's test. AICAR: AMPK activator 5-aminoimidazole-4carboxamide-1- $\beta$-D-ribonucleoside; EC: tannase-converted green tea extract containing a high epicatechin content; CT: green tea extract

altered the transcriptional control of gene expression in the skeletal muscles (Fig. 1c-e).

\section{The effects of Tannase-converted green tea extract on transcription factors}

The effects of EC on the gene expression of FOXO1 and FOXO3 in $\mathrm{C} 2 \mathrm{C} 12$ cells treated in media with AICAR, EC, and $\mathrm{CT}$ for $12 \mathrm{~h}$ are shown in Fig. 2. Transcript levels for FOXO1 were significantly higher in the AICAR, EC, and CT groups (Fig. 2a, AICAR: 1.58-fold, $P<0.05$; EC: 2.00-fold, $P<0.05$; CT: 1.98 -fold, $P<0.05)$ than those in the control group. Additionally, $\mathrm{C} 2 \mathrm{C} 12$ cells treated in the $\mathrm{EC}$ group showed significantly increased transcript levels for FOXO3, as compared to those observed for the control group (Fig. 2b, EC vs. control, 1.27 -fold increase, $P<0.05$ ). There was no significant difference in the mRNA levels of FOXO3 in the AICAR and CT groups, as compared to those for the control group $(P>0.05)$. In Fig. 3 , this study investigated the effects of EC on FOXO transcription factors in $\mathrm{C} 2 \mathrm{C} 12$ cells.

The effects of Tannase-converted green tea extract on the mTOR/S6K pathway

The effects of EC on levels of mTOR and pS6K proteins are presented in Fig. 3 and Additional file 3. The mTOR protein levels of $\mathrm{C} 2 \mathrm{C} 12$ skeletal muscle cells were significantly increased by treatment with $5 \mu \mathrm{g} / \mathrm{mL} \mathrm{CT}$, as compared to those of the control group (Fig. 4b, CT vs. control, 1.69-fold increase, $P<0.05$ ) In addition, the pS6K levels of the CT group were significantly different from those of the EC group (Fig. 3c, CT vs. EC, 1.54-fold increase, $P<0.05$ ). However, no significant differences were observed in the levels of mTOR and $\mathrm{pS6K}$ proteins in the AICAR and the EC groups, as compared to those of the control group $(P>0.05)$. To better understand the effect of EC on cellular and molecular mechanisms, western blotting was utilized, and the protein levels in the mTOR/S6K pathway were analyzed (Fig. 3).

\section{The effects of Tannase-converted green tea extract on} oxidative stress-induced C2C12 Myogenesis and oxidative stress-related genes

To understand the effects of EC on oxidative stressinduced $\mathrm{C} 2 \mathrm{C} 12$ myogenesis, morphological changes due to oxidative stress that were induced by $100 \mu \mathrm{M}$ of $\mathrm{H}_{2} \mathrm{O}_{2}$ were observed. The morphological changes in the $\mathrm{C} 2 \mathrm{C} 12$ cells treated with AICAR, EC, and CT were measured using Giemsa staining, 2 days after exposure to $100 \mu \mathrm{M} \mathrm{H}_{2} \mathrm{O}_{2}$ (Fig. 4 and Additional file 2). Figure $4 \mathrm{~b}$ shows that the C2C12 cells exposed to $\mathrm{H}_{2} \mathrm{O}_{2}$ experienced significantly inhibited myogenic differentiation. The myotube density was significantly higher in the AICAR-treated group (vs. control, 1.47-fold increase, $P<0.05$ ) and EC group (EC vs. control, 1.32-fold increase, $P<0.05)$. Considering the effects 

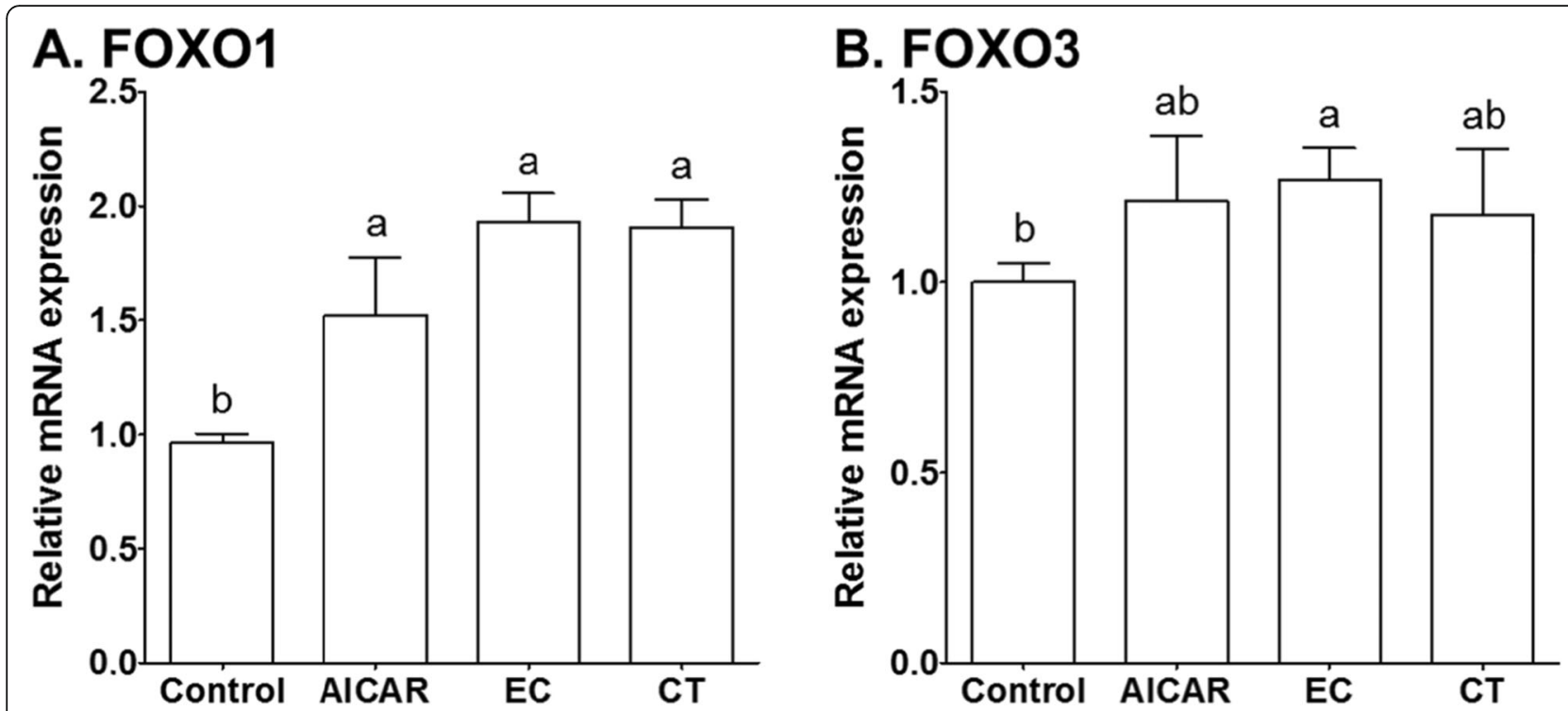

Fig. 2 The effects of tannase-treated catechin on the gene expression of (a) FOXO1 and (b) FOXO3 in C2C12 skeletal muscle cells. Each value represents the mean \pm SE. Different letters indicate significant differences at $P<0.05$ according to Tukey's test. AICAR: AMPK activator 5aminoimidazole-4-carboxamide-1- $\beta$-D-ribonucleoside; EC: tannase-converted green tea extract containing high epicatechin content; CT: green tea extract

of $\mathrm{CT}$ in oxidative stress-induced $\mathrm{C} 2 \mathrm{C} 12$ cells, no significant difference in morphological changes were observed, in comparison to those of the control group $(P>0.05)$. The morphological changes induced by $\mathrm{H}_{2} \mathrm{O}_{2}$ have been shown to be caused by oxidative damage, associated with an increase in ROS in cells. Therefore, it was evaluated whether the antioxidant regulation of EC mediates SOD, CAT, and GST gene expression under $\mathrm{H}_{2} \mathrm{O}_{2}$-induced stress. Treatment with CT significantly increased SOD levels approximately $44 \%$, as compared to those of the AICAR-treatment group (Fig. 4c, $P<0.05$ ). The mRNA expression of catalase, another antioxidant enzyme, was significantly induced by $50 \%$ in the green tea extract group, as compared to that of the control group (Fig. 4c, $P<0.05$ ). In addition, green tea extract treatment greatly increased the mRNA level of GST, as compared with that of the control, AICAR, and EC groups (Fig. 4c, $P<0.05$ ). These results indicated that AICAR and EC did not affect mRNA levels of antioxidant enzymes, as compared with those of enzymes associated with the morphological change analysis. The data obtained in this study showed that EC effectively suppressed the increase in oxidative stress induced by $\mathrm{H}_{2} \mathrm{O}_{2}$, thereby ameliorating myotube formation (Fig. 4). Additionally, the effects of EC on SOD, CAT, and GST mRNA levels were studied in oxidative stress-induced $\mathrm{C} 2 \mathrm{C} 12$ skeletal muscle cells (Fig. 4). However, EC did not have a significant effect on mRNA levels of antioxidant enzymes such as SOD, CAT, and GST. The presence of reactive oxygen species (ROS) has been reported in various muscular disorders, and it is associated with cell injury. These results indicated that EC provided protection against $\mathrm{H}_{2} \mathrm{O}_{2}$-induced oxidative stress in $\mathrm{C} 2 \mathrm{C} 12$ cells, which was a result of the radical scavenging effect.

\section{The effects of Tannase-converted green tea extract on AMPK activity}

To investigate whether the AMPK-dependent mechanism of EC involved a translation process under oxidative stress conditions, the levels of AMPK $\alpha$ and MuRF-1 proteins were determined (Fig. 5 and Additional file 4). Protein levels for AMPK $\alpha$ in normal C2C12 cells of the AICAR group were 1.28-fold higher than that of the control group $(P<0.05)$. In addition, the AMPK $\alpha$ levels in oxidative stress-induced $\mathrm{C} 2 \mathrm{C} 12$ cells of the AICAR group were significantly decreased by $\mathrm{H}_{2} \mathrm{O}_{2}$ exposure, as compared to those of the control group and EC group (Fig. 5b, $P<$ 0.05). The AMPK $\alpha$ levels of the EC and CT groups were not significantly different in from those of the control group (Fig. 5b, $P>0.05$ ). However, the AICAR, EC, and $\mathrm{CT}$ groups did not show significant differences in the levels of MuRF-1 proteins, as compared to those of the control group (Fig. 5c). As shown in Fig. 5c, oxidative stress-induced $\mathrm{C} 2 \mathrm{C} 12$ cells treated with green tea extract showed significantly different MuRF-1 levels, as compared to those of the control and EC groups (Fig. 5b, $P>0.05$ ). As shown in Fig. 5, the results found that the treatment of EC increase the levels of AMPK $\alpha$ and MuRF-1 proteins in oxidative stress-induced $\mathrm{C} 2 \mathrm{C} 12$ cells. AMPK is the central regulator of metabolism in cells and organisms, and has recently been known to increase myofibrillar protein degradation through the expression of muscle atrophy F-box (MAFbx) and MuRF1 [19]. In addition, the 
A

\section{C2C12}

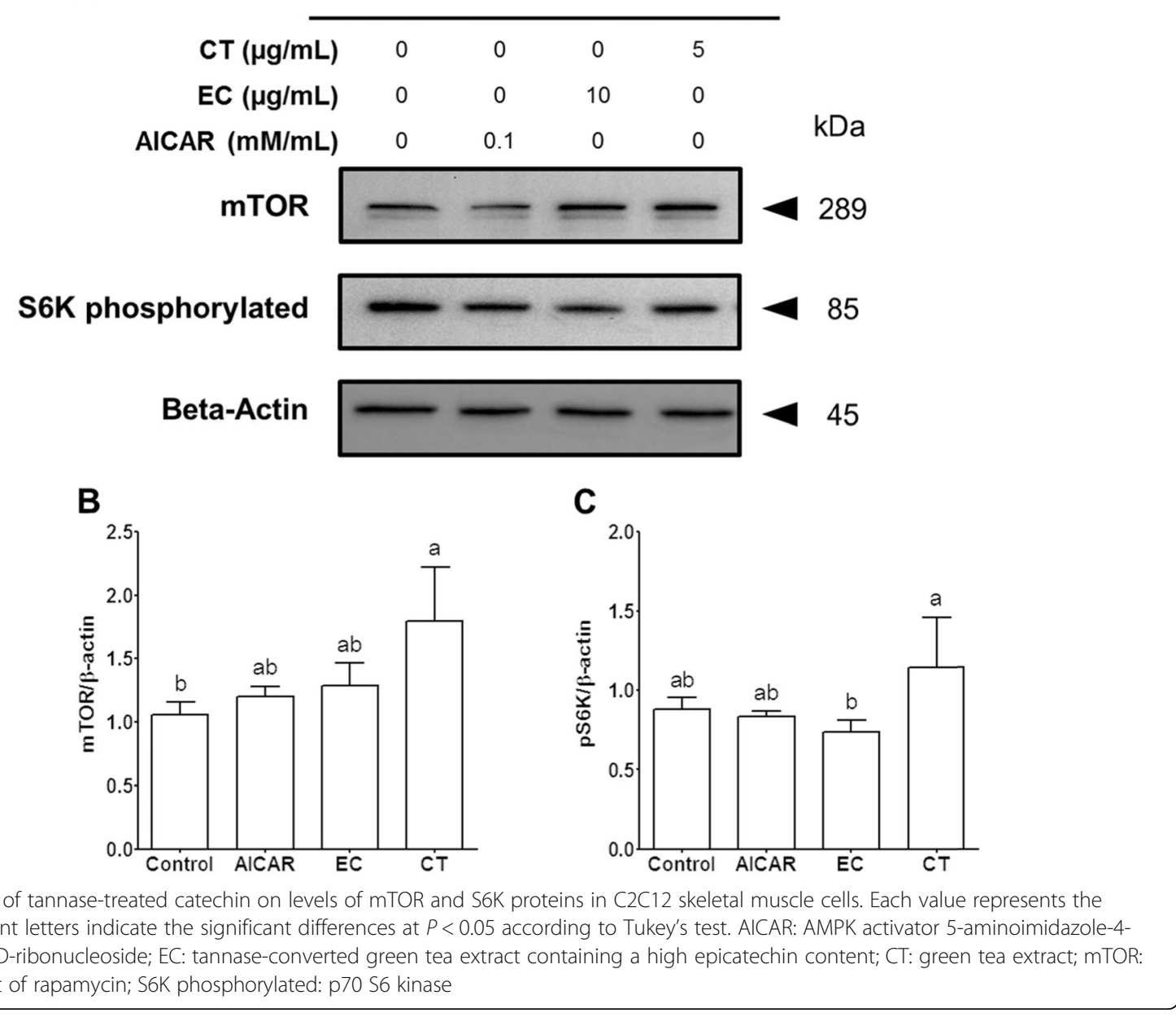

downregulation of atrogin-1 and MuRF1 gene expression, which was involved in the regulation of attenuation of muscle wasting, was investigated.

\section{Discussion}

The four major catechins in green tea extract include approximately 59\% EGCG, 19\% EGC, 13.6\% ECG, and 6.4\% EC [20], and green tea also contains GA and other phenolic acids, such as caffeic acid. Baik et al. reported that the addition of green tea extract along with tannase treatment significantly increased the biotransformation of catechins, and pectinase-driven hydrolysis significantly increased interleukin-6 (IL-6) production in macrophages [21]. Dietary polyphenols, including EGCG, resveratrol, and curcumin are associated with the regulation of systemic inflammation and might relieve symptoms of muscle dysfunction [22]. In addition, the AICAR-induced activation of AMPK had an additive effect on glucose transporter-1 (GLUT1) and GLUT4 expression in skeletal muscle, which lead to translocation, which is known to increase the glucose transport response and mitochondrial biogenesis [23].
Lee et al. reported a dose-dependent effect of EC on the protein levels of MHC, MyoD and myogenin, and stimulation of promyogenic signaling pathways, p38 MAPK and Akt, in EC-treated C2C12 myoblasts [24]. In addition, Gutierrz-Salmean et al. proved that EC treatment resulted in a significant increase in the levels of MEF2, Myf5, MyoD, and myogenin in the skeletal muscles of old EC-treated mice ( 25 months) and the muscle strength in human hands [25]. Experimental evidence found using HepG2 cells and C2C12 skeletal muscle myotubes demonstrated that FOXO transcription factors are sufficient for activating and increasing the levels of a MuRF1 promotor fragment, atrogin-1, and/or MuRF1 mRNA expression [26]. In the skeletal muscle of aged mice, it has been reported that the levels of FOXO3 protein is reduced by $25 \%$, but that there was no change in FOXO1 levels [27]. Phytochemicals, including polyphenols, have been shown to upregulate the functioning of FOXO proteins. The EGCG treatment of rats aged 5 weeks has shown to increase the levels of FOXO3, sirtuin 1, SOD, glutathione peroxidase levels, and their 
A

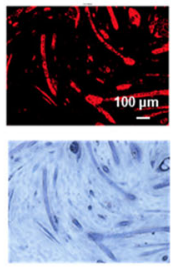

Control
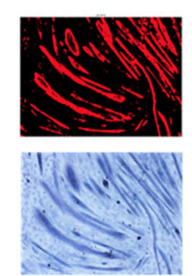

AICAR $0.1 \mathrm{mM}$

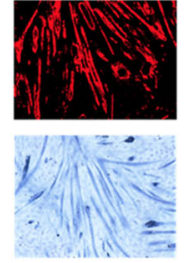

EC $10 \mu \mathrm{g} / \mathrm{mL}$
B

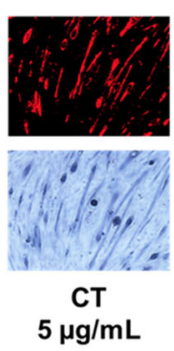

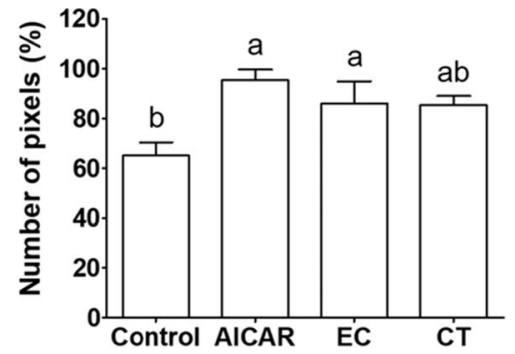

D. CAT

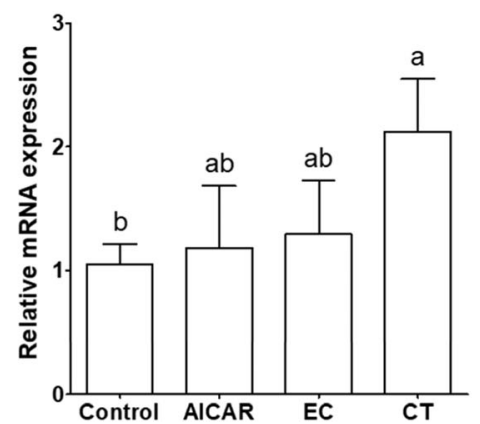

\section{E. GST}

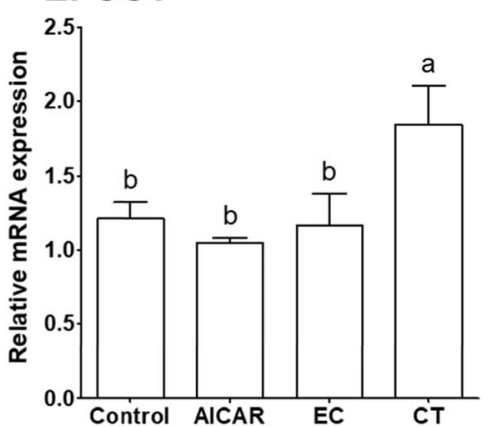

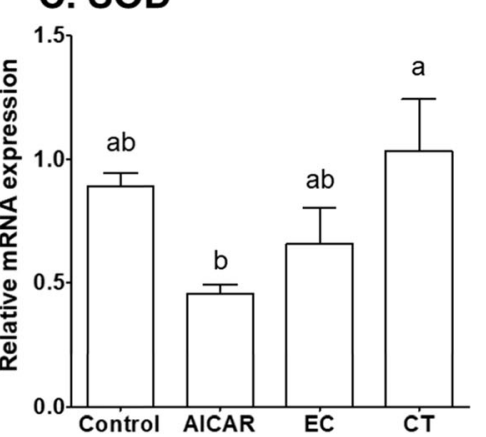

Fig. 4 The effects of tannase-treated catechin on (a and $\mathbf{b}$ ) myotube formation and the gene expression of (c) SOD (d) CAT and (e) GST in oxidative stress-induced $\mathrm{C} 2 \mathrm{C} 12$ skeletal muscle cells. Each value represents the mean \pm SE. Different letters indicate significant differences at $P<$ 0.05, according to Tukey's test. AICAR: AMPK activator 5-aminoimidazole-4-carboxamide-1- $\beta$-D-ribonucleoside; EC: tannase-converted green tea extract containing a high epicatechin content; $\mathrm{CT}$ : green tea extract

lifespan [28]; the polyphenol curcumin is involved in inhibiting FOXO3 phosphorylation, causing a 2-fold increase in FOXO3-mediated gene expression [29].

AICAR, the positive control, is known to be a direct activator of AMPK that prevents the characteristic increase in muscle protein synthesis that occurs with alterations in mTOR signal transduction [30]. The crosstalk between mTOR/S6K signaling and AMPK is known as the molecular mechanism that controls skeletal muscle mass, and these results have explained both the catabolism and anabolism of skeletal muscle using genetic and pharmacological evidence [31]. Natural products, including EGCG, curcumin, resveratrol, and caffeine have been found to inhibit the mTOR signaling pathway and downstream effector molecules, such as S6K1 [32].

Murakami et al. reported that EC $(6.2 \mu \mathrm{M})$ had a slightly higher 1,1-diphenyl-2-picrylhydrazyl (DPPH) radical-scavenging activity $\left(\mathrm{EC}_{50}\right)$ than catechin $(7.7 \mu \mathrm{M})$ [33], and Hong et al. provided specific evidence for the fact that tannase-converted green tea extract has the potential to attenuate UVB-induced oxidative stress in mice skin after the analysis of glutathione (GSH) and hydrogen peroxide levels [34]. In addition, the antioxidant enzyme activity and levels of GSH in $\mathrm{C} 2 \mathrm{C} 12$ cells were increased after treatment with polyphenol-rich green tea extract, which thus acted against the oxidative stress caused by mycotoxin citrinin [35].

Flavanol-rich extract and other phenolic compounds are regulated by the genetic expression of atrogin- 1 and MuRF1, which alleviated muscle loss and improved impaired myotube formation [36]. In our results, the inhibition of MuRF1 protein levels by $\mathrm{EC}$ in oxidative stress-induced $\mathrm{C} 2 \mathrm{C} 12$ cells improved impaired myotube formation. Until an approximate age of 40 years, skeletal muscle mass and strength are preserved, but these are reduced to $50 \%$ by the age of 80 [37]. Physical activity in the elderly population is limited by sarcopenia, and is associated with a variety of diseases [38]. Therefore, new pharmacological strategies to effectively treat sarcopenia in the elderly can be viewed as a preventive measure. Tannase is an inducible enzyme and decomposes ester bonds in hydrolyzable tannins to produce glucose and gallic acid. It is known that the treatment of green tea with tannase improves the extraction efficiency of polyphenols and increases the radical scavenging ability [14]. Although green tea extract is being investigated in various studies regarding muscle function, recovery, and fibers [39], few studies have evaluated the relationship between skeletal muscle mass and tannase-converted green tea extract. Therefore, this study aimed to investigate the effects of tannase-converted green tea extract 


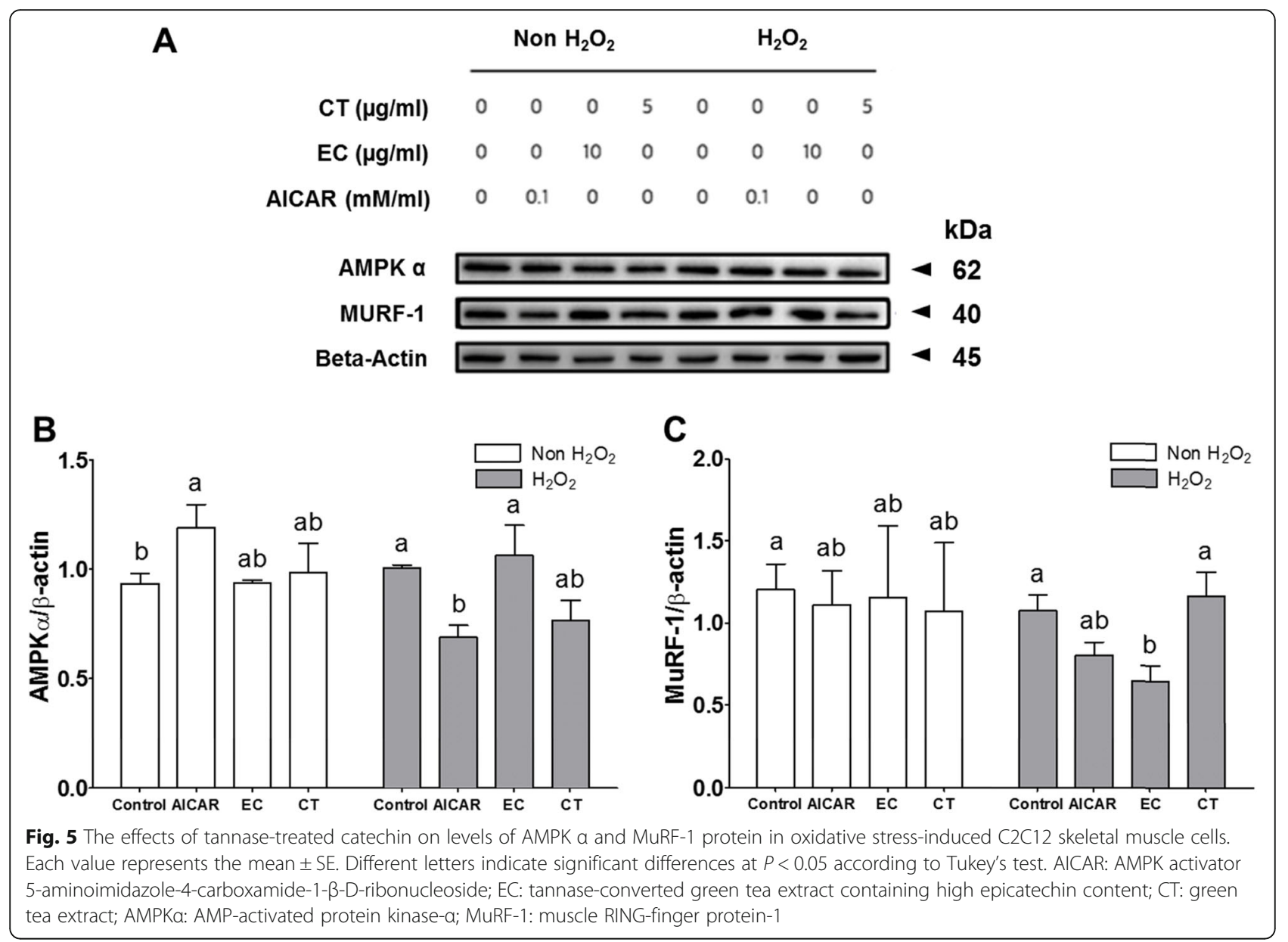

with a high EC, EGC, and gallic acid (GA) content on cellular morphological changes and intercellular signaling pathways, using well-characterized models of normal $\mathrm{C} 2 \mathrm{C} 12$ and oxidative stress-induced $\mathrm{C} 2 \mathrm{C} 12$ skeletal muscle cells.

\section{Conclusions}

In conclusion, as compared to CT, the green tea extract converted to hydrolyzed tannase contributed to a greater improvement in myotube formation and protective properties against $\mathrm{H}_{2} \mathrm{O}_{2}$-induced oxidative stress in $\mathrm{C} 2 \mathrm{C} 12$ cells. The effects of EC with a high EC, EGC, and GA content were demonstrated by an improvement in the regulation of muscle regulatory factors, transcription factors, and the mTOR/S6K pathway, as well as by Giemsa staining analysis. The properties of EC are considered to be a result of the radical scavenging ability and downregulation of MuRF1 protein levels in oxidative stress-induced cells. Taken together, these results suggest that EC with a high EC, EGC, and GA content can be used as a supplement for alleviating muscle loss in $\mathrm{C} 2 \mathrm{C} 12$ skeletal muscle cells. Moreover, the outcomes of this study are expected to shed light on cellular and molecular mechanisms for further understanding the functional and pharmacological properties of botanical extracts, their enzymatic hydrolysis, and their therapeutic potentials for sarcopenia. Further in vivo studies for the myostatin and follystatin signaling pathways are necessary, irrespective of whether the myogenin expression observed in this study was caused because of them or by inflammatory cytokine pathway regulation. In summary, this study supports that tannase-converted green tea extract is the principal material that modulates intracellular signaling pathways to prevent or treat muscle atrophy.

\section{Supplementary information}

Supplementary information accompanies this paper at https://doi.org/10. 1186/s12906-020-2827-7.

Additional file 1: Figure S1 Raw data for Fig. 1.

Additional file 2: Figure S2 Raw data for Fig. 4.

Additional file 3: Figure S3 Raw data for Fig. 3.

Additional file 4: Figure $\mathbf{5 4}$ Raw data for Fig. 5.

\section{Abbreviations}

AICAR: AMPK activator 5-aminoimidazole-4-carboxamide-1- $\beta$-D-ribonucleoside; AMPKa: AMP-activated protein kinase-a; IL: Interleukin; MAFbx: Muscle atrophy F-box; MuRF-1: Muscle RING-finger protein-1; ROS: Reactive oxygen species 


\section{Acknowledgments}

Not applicable.

\section{Authors' contributions}

This topic was designed by JM and YP; KH, SL, JH and DK carried out molecular studies, the research process, data analysis and writing paper. All authors read and approved the final manuscript.

\section{Funding}

The experimental design, the preparation of sample, the analysis of animals and the interpretation of results data for this research was mainly supported by the Technology development program (S2449634) funded by the Ministry of SMEs and Startups (MSS, Republic of Korea).

\section{Availability of data and materials}

The dataset generated during the present study is available upon reasonable request to the author (Prof. Yooheon Park).

\section{Ethics approval and consent to participate}

We had complied with the ethics standard for research activity established at Dongguk University.

\section{Consent for publication}

Not applicable.

\section{Competing interests}

The authors declare that they have no competing interests.

\section{Author details}

'BK21 Plus, College of Health Science, Korea University, Seoul 02841, Republic of Korea. ${ }^{2}$ Department of Food Science and Technology, Chung-Ang University, Anseong 17546, Republic of Korea. ${ }^{3}$ Animal Center and Preclinical Evaluation Research Institute, Yonam College, Cheonan 31005, Republic of Korea. ${ }^{4}$ BTC Corporation, \#703, Technology Development Center, 705 Haean-ro, Sangnok-gu, Ansan-si, Gyeonggi-do, Republic of Korea. ${ }^{5}$ Department of Food Science and Biotechnology, Dongguk University, Goyang 10326, Republic of Korea.

Received: 30 April 2019 Accepted: 23 January 2020 Published online: 11 February 2020

\section{References}

1. Kubben N, Misteli T. Shared molecular and cellular mechanisms of premature ageing and ageing-associated diseases. Nat Rev Mol Cell Biol. 2017:18(10):595-609.

2. Rosenberg $\mathrm{H}$. Sarcopenia: origins and clinical relevance. Clin Geriatr Med. 2011:27(3):337-9.

3. Walston JD. Sarcopenia in older adults. Curr Opin Rheumatol. 2012;24(6):623-7.

4. Musumeci G, Castrogiovanni P, Coleman R, Szychlinska MA, Salvatorelli L, Parenti R, Magro G, Imbesi R. Somitogenesis: From somite to skeletal muscle. Acta Histochem. 2015;117(4-5):313-28.

5. Derbre F, Gratas-Delamarche A, Gomez-Cabrera MC, Vina J. Inactivityinduced oxidative stress: a central role in age-related sarcopenia? Eur J Sport Sci. 2014;14(Suppl 1):S98-108

6. Musumeci G. Sarcopenia and exercise "the state of the art". J Funct Morphol Kinesiol. 2017:2(4):40.

7. Trovato FM, Castrogiovanni P, Szychlinska MA, Purrello F, Musumeci G. Impact of Western and Mediterranean Diets and Vitamin D on Muscle Fibers of Sedentary Rats. Nutrients. 2018;10(2):231.

8. Szychlinska MA, Castrogiovanni P, Trovato FM, Nsir H, Zarrouk M, Lo Furno D, Di Rosa M, Imbesi R, Musumeci G. Physical activity and Mediterranean diet based on olive tree phenolic compounds from two different geographical areas have protective effects on early osteoarthritis, muscle atrophy and hepatic steatosis. Eur J Nutr. 2019;58(2):565-81.

9. Rondanelli M, Miccono A, Peroni G, Guerriero F, Morazzoni P, Riva A, Guido D, Perna S. A systematic review on the effects of botanicals on skeletal muscle health in order to prevent sarcopenia. Evid Based Complement Altern Med. 2016;2016:5970367.

10. Banerjee S, Chatterjee J. Efficient extraction strategies of tea (Camellia sinensis) biomolecules. J Food Sci Technol. 2015;52(6):3158-68.
11. Ni CX, Gong H, Liu Y, Qi Y, Jiang CL, Zhang JP. Green tea consumption and the risk of liver Cancer: a meta-analysis. Nutr Cancer. 2017;69(2):211-20.

12. Hsu SP, Wu MS, Yang CC, Huang KC, Liou SY, Hsu SM, Chien CT. Chronic green tea extract supplementation reduces hemodialysis-enhanced production of hydrogen peroxide and hypochlorous acid, atherosclerotic factors, and proinflammatory cytokines. Am J Clin Nutr. 2007:86(5):1539-47.

13. Ho CT, Chen Q, Shi H, Zhang KQ, Rosen RT. Antioxidative effect of polyphenol extract prepared from various Chinese teas. Prev Med. 1992;21(4):520-5.

14. Hong YH, Jung EY, Park Y, Shin KS, Kim TY, Yu KW, Chang UJ, Suh HJ. Enzymatic improvement in the polyphenol extractability and antioxidant activity of green tea extracts. Biosci Biotechnol Biochem. 2013;77(1):22-9.

15. Shay J, Elbaz HA, Lee I, Zielske SP, Malek MH, Huttemann M. Molecular mechanisms and therapeutic effects of (-)-Epicatechin and other polyphenols in Cancer, inflammation, diabetes, and Neurodegeneration. Oxidative Med Cell Longev. 2015;2015:181260.

16. Record IR, Lane JM. Simulated intestinal digestion of green and black teas. Food Chem. 2001:73(4):481-6.

17. Velica $P$, Bunce CM. A quick, simple and unbiased method to quantify C2C12 myogenic differentiation. Muscle Nerve. 2011:44(3):366-70.

18. Livak KJ, Schmittgen TD. Analysis of relative gene expression data using real-time quantitative PCR and the 2(-Delta Delta $C(T))$ method. Methods. 2001;25(4):402-8.

19. Nakashima K, Yakabe $Y$. AMPK activation stimulates myofibrillar protein degradation and expression of atrophy-related ubiquitin ligases by increasing FOXO transcription factors in C2C12 myotubes. Biosci Biotechnol Biochem. 2007;71(7):1650-6.

20. McKay DL, Blumberg JB. The role of tea in human health: an update. J Am Coll Nutr. 2002;21(1):1-13.

21. Baik JH, Shin KS, Park Y, Yu KW, Suh HJ, Choi HS. Biotransformation of catechin and extraction of active polysaccharide from green tea leaves via simultaneous treatment with tannase and pectinase. J Sci Food Agric. 2015;95(11):2337-44.

22. Legeay S, Rodier M, Fillon L, Faure S, Clere N. Epigallocatechin Gallate: a review of its beneficial properties to prevent metabolic syndrome. Nutrients. 2015:7(7):5443-68.

23. Egawa T, Ohno Y, Goto A, Ikuta A, Suzuki M, Ohira T, Yokoyama S, Sugiura T, Ohira Y, Yoshioka T, et al. AICAR-induced activation of AMPK negatively regulates myotube hypertrophy through the HSP72-mediated pathway in C2C12 skeletal muscle cells. Am J Phys Endocrinol Metab. 2014;306(3):E344-54.

24. Lee SJ, Leem YE, Go GY, Choi Y, Song YJ, Kim I, Kim DY, Kim YK, Seo DW, Kang JS, et al. Epicatechin elicits MyoD-dependent myoblast differentiation and myogenic conversion of fibroblasts. PLoS One. 2017;12(4):e0175271.

25. Gutierrez-Salmean G, Ciaraldi TP, Nogueira L, Barboza J, Taub PR, Hogan MC Henry RR, Meaney E, Villarreal F, Ceballos G, et al. Effects of (-)-epicatechin on molecular modulators of skeletal muscle growth and differentiation. J Nutr Biochem. 2014:25(1):91-4

26. McLoughlin TJ, Smith SM, DeLong AD, Wang H, Unterman TG, Esser KA. FoxO1 induces apoptosis in skeletal myotubes in a DNA-binding-dependent manner. Am J Physiol Cell Physiol. 2009;297(3):C548-55.

27. Furuyama T, Yamashita H, Kitayama K, Higami Y, Shimokawa I, Mori N. Effects of aging and caloric restriction on the gene expression of Foxo1, 3, and 4 (FKHR, FKHRL1, and AFX) in the rat skeletal muscles. Microsc Res Tech. 2002;59(4):331-4

28. Niu Y, Na L, Feng R, Gong L, Zhao Y, Li Q, Li Y, Sun C. The phytochemical, EGCG, extends lifespan by reducing liver and kidney function damage and improving age-associated inflammation and oxidative stress in healthy rats. Aging Cell. 2013:12(6):1041-9.

29. Zingg JM, Hasan ST, Cowan D, Ricciarelli R, Azzi A, Meydani M. Regulatory effects of curcumin on lipid accumulation in monocytes/macrophages. J Cell Biochem. 2012;113(3):833-40.

30. Pruznak AM, Kazi AA, Frost RA, Vary TC, Lang CH. Activation of AMPactivated protein kinase by 5-aminoimidazole-4-carboxamide-1-beta-Dribonucleoside prevents leucine-stimulated protein synthesis in rat skeletal muscle. J Nutr. 2008:138(10):1887-94

31. Yoon MS. mTOR as a key regulator in maintaining skeletal muscle mass. Front Physiol. 2017:8:788.

32. Zhou H, Luo Y, Huang S. Updates of mTOR inhibitors. Anti Cancer Agents Med Chem. 2010:10(7):571-81.

33. Murakami Y, Kawata A, Ito S, Katayama T, Fujisawa S. Radical-scavenging and anti-inflammatory activity of Quercetin and related compounds and their combinations against RAW264.7 cells stimulated with Porphyromonas gingivalis fimbriae. Relationships between anti-inflammatory activity and quantum chemical parameters. In vivo. 2015;29(6):701-10. 
34. Hong YH, Jung EY, Shin KS, Kim TY, Yu KW, Chang UJ, Suh HJ.

Photoprotective effects of a formulation containing tannase-converted green tea extract against UVB-induced oxidative stress in hairless mice. Appl Biochem Biotechnol. 2012;166(1):165-75.

35. Sharath Babu GR, Ilaiyaraja N, Khanum F, Anand T. Cytoprotective propensity of green tea polyphenols against citrinin-induced skeletalmyotube damage in C2C12 cells. Cytotechnology. 2017;69(4):681-97.

36. Liu HW, Chen YJ, Chang YC, Chang SJ. Oligonol, a Low-Molecular Weight Polyphenol Derived from Lychee, Alleviates Muscle Loss in Diabetes by Suppressing Atrogin-1 and MuRF1. Nutrients. 2017;9(9):E1040.

37. Metter EJ, Conwit R, Tobin J, Fozard JL. Age-associated loss of power and strength in the upper extremities in women and men. J Gerontol A Biol Sci Med Sci. 1997;52(5):B267-76.

38. Janssen I, Heymsfield SB, Ross R. Low relative skeletal muscle mass (sarcopenia) in older persons is associated with functional impairment and physical disability. J Am Geriatr Soc. 2002;50(5):889-96.

39. Alway SE, Bennett BT, Wilson JC, Sperringer J, Mohamed JS, Edens NK, Pereira SL. Green tea extract attenuates muscle loss and improves muscle function during disuse, but fails to improve muscle recovery following unloading in aged rats. J Appl Physiol. 2015;118(3):319-30.

\section{Publisher's Note}

Springer Nature remains neutral with regard to jurisdictional claims in published maps and institutional affiliations.

Ready to submit your research? Choose BMC and benefit from:

- fast, convenient online submission

- thorough peer review by experienced researchers in your field

- rapid publication on acceptance

- support for research data, including large and complex data types

- gold Open Access which fosters wider collaboration and increased citations

- maximum visibility for your research: over $100 \mathrm{M}$ website views per year

At BMC, research is always in progress.

Learn more biomedcentral.com/submissions 